\title{
Diagrams and metaphors: Iconic aspects in language*
}

\author{
Masako K. Hiraga \\ Faculty of Liberal Arts, The University of the Air, 2-11 Wakaba, Mihama-ku, Chiba City, 261, Japan
}

\begin{abstract}
The problem of iconicity has been a recurring theme in linguistic inquiry into the nature of the linguistic sign. The property of iconicity includes not only the narrow category of sound symbolism, but also the broad categories of isomorphism and metaphor. This paper surveys recent research, and offers a classification of diagrammatic and metaphorical iconicity in language. Problems of structural diagram, relational diagram, grammatical metaphor, conventional metaphor and poetic metaphor are discussed, with a few illustrative examples. This review shows that an evaluation of the property of iconicity in language has implications for the general theory of language as a 'natural' phenomenon.
\end{abstract}

\section{Introduction}

The problem of iconicity has been a recurring theme in linguistic inquiry into the nature of the linguistic sign. Plato's dialogue Cratylus, for example, reminds us of the debate whether the relationship of form and content in language is set physei (by nature) or nomōi, ethei (by agreement and convention) (Plato St I 384d, English translation 1926: 7). Roman Jakobson revived this theme in his critique of Ferdinand de Saussure's notion of the arbitrariness of the linguistic sign (Jakobson, 1971 [1965]). ${ }^{1}$ He applied Charles Sanders Peirce's typology of signs to argue that lan-

* I am indebted to Yasuo Isami, John Robert Ross, Linda R. Waugh, and Joanna Radwanska-Williams for their invaluable comments on an earlier version of this paper.

1 Saussure asserts that the nature of the association between the signifier and the signified was arbitrary, i.e., not based on any inherent resemblance (de Saussure, 1959: 67 [1916]). Although he sees the arbitrariness of the linguistic sign as a fundamental principle of the linguistic sign, he also admits that the linguistic system itself, the way certain parts of the mass of signs are combined and ordered, is relatively motivated, i.e., the limiting of arbitrariness. "Everything that relates to language as a system must, I am convinced, be approached from this viewpoint, which has scarcely received the attention of linguists: the limiting of arbitrariness. This is the best possible basis for approaching the study of language as a system. In fact, the whole system of language is based on the irrational principle of the arbitrariness of the sign, which would lead to the worst sort of complication if applied without restriction. But the mind contrives to introduce a principle of order and regularity into certain parts of the mass of signs, and this is the role of relative motivation" (ibid.: p. 133). 
guage also has the non-arbitrary property of iconicity, or association by similarity between form and meaning, and of indexicality of artifice.

The property of iconicity includes not only the narrow category of sound-symbolism, but also the broad categories of isomorphism and metaphor. This paper will survey the recent research, and offer a classification of diagrammatic and metaphorical iconicity in language. ${ }^{2}$ Haiman $(1985 a, b)$ deals most extensively with the problem of diagrammatic iconicity, whereas Lakoff (1987), Langacker (1987, 1991), Sweetser (1990), etc. have broken ground in the area of cognitive linguistics, which has a strong bearing on both diagrammatic and metaphorical iconicity. Problems of structural diagram, relational diagram, grammatical metaphor, conventional metaphor and poetic metaphor will be discussed, with a few illustrative examples.

I believe that a review of this kind will show that an evaluation of the property of iconicity in language has implications for the general theory of language as a 'natural' phenomenon.

\section{Peircean iconicity}

Let us briefly review the Peircean trichotomy of the sign, which we shall use as a frame of reference for our discussion. Peirce (1955 [1902]) divides signs in relation to their objects into three types: icons, indices, and symbols. ${ }^{3}$ An icon is defined as a sign which represents an object mainly by its similarity to that object; an index as a sign which represents its object by its existential relation to the object; and a symbol as a sign which signifies its object by a law or a convention.

Icons are divided further into three subtypes, i.e., images, diagrams and metaphors, based on the degree of abstraction as well as the dominance of characteristics of similarity such as mimicry, analogy and parallelism. ${ }^{4}$ Image (e.g., a portrait of a person) achieves similarity by partaking of some of the simple qualities of its object (e.g., the person portrayed). The relation between the image and its object is based on a monadic, simple, sensory or mimetic resemblance. Diagrams (e.g.,

2 Charles S. Peirce classifies the icons into three subtypes: images, diagrams and metaphors (Peirce, 1955: 102-105 [1902]). This article, however, does not discuss image iconicity in language, which is basically the problem of onomatopoeia and sound symbolism.

3 "An Icon is a sign which refers to the Object that it denotes merely by virtue of characters of its own, and which it possesses, just the same, whether any such Object actually exists or not" (Peirce. 1955: 102 [1902]). "... such as a lead-pencil streak as representing a geometrical line"” (ibid.: p. 104). "An Index is a sign which refers to the Object that it denotes by virtue of being really affected by that object" (ibid.: p. 102). "... Such, for instance, is a piece of mould with a bullet-hole in it as sign of a shot" (ibid.: p. 104). "A Symbol is a sign which refers to the Object that it denotes by virtue of a law, usually an association of general ideas, which operates to cause the Symbol to be interpreted as referring to that Object" (ibid.: p. 102). "... Such is any utterance of speech which signifies what it does only by virtue of its being understood to have that signification" (ibid.: p. 104, italics in the original).

${ }_{4}$ "Those which partake of simple qualities, or First Firstness, are images; those which represent the relations, mainly dyadic, or so regarded, of the parts of one thing by analogous relations in their own parts, are diagrams; those which represent the representative character of a representamen by representing a parallelism in something else, are metaphors" (Peirce, 1955: 105 [1902]; italics in the original). 
maps and floor plans) exhibit a structure analogous to the structure of their object (e.g., territories and buildings). Diagrams show relations of the parts of object by analogous relations in their own parts. The similarity between the diagram and its object is a dyadic, relational or structural analogy. Metaphors represent a parallelism in something else. A metaphorical icon (e.g., "My love is a rose") signifies its object (e.g., 'my love') by pointing to a parallelism between the object (e.g., 'my love') and something else (e.g., 'a rose'). The immediacy of sign-object link decreases from images to diagrams, from diagrams to metaphors. At the same time, an icon may involve all the three subtypes with predominance of one over the others.

Table 1

Subtypes of icon according to Peirce

\begin{tabular}{|c|c|c|c|}
\hline Subtypes & Image & Diagram & Metaphor \\
\hline $\begin{array}{l}\text { How similarity } \\
\text { is achieved }\end{array}$ & $\begin{array}{l}\text { partakes of some of } \\
\text { the simple qualities } \\
\text { of its object }\end{array}$ & $\begin{array}{l}\text { exhibits the abstract } \\
\text { structure of its object }\end{array}$ & $\begin{array}{l}\text { represents a parallelism } \\
\text { in something else }\end{array}$ \\
\hline Similarity in & quality & structure & association \\
\hline $\begin{array}{l}\text { Sign-Object (Sign) } \\
\text { relationship }\end{array}$ & $\begin{array}{l}\text { monadic } \\
\text { immediate mimicry }\end{array}$ & $\begin{array}{l}\text { dyadic } \\
\text { structural or } \\
\text { relational analogy }\end{array}$ & $\begin{array}{l}\text { triadic } \\
\text { representational } \\
\text { parallelisin }\end{array}$ \\
\hline $\begin{array}{l}\text { Manifestations in } \\
\text { language }\end{array}$ & $\begin{array}{l}\text { onomatopoeia } \\
\text { sound symbolism }\end{array}$ & $\begin{array}{l}\text { linearity, proximity, } \\
\text { symmetry, } \\
\text { asymmetry, etc. }\end{array}$ & $\begin{array}{l}\text { metaphorical transfer } \\
\text { from one domain to } \\
\text { another }\end{array}$ \\
\hline
\end{tabular}

Table 1 summarizes the main characteristics of the subtypes of icons with possible manifestations in language as examples.

\section{Diagrammatic iconicity}

As a diagram refers to its object by virtue of similarity between the relationship among the parts of the diagram and the relationship among the parts of the object, the structure of linguistic representation sometimes resembles the structure of the content $^{5}$ that it conveys. For instance, the syntagmatic order of mention in speech corresponds to the chronological or causal order in which the event occurs, as in Caesar's "veni, vidi, vici" (I came, I saw, I conquered) (cf. Jakobson, 1965: 350). Paradigmatically, word affinity relations such as morphemes (e.g., 'acceptable',

\footnotetext{
5 The term 'content' is employed here rather loosely. It designates a wide range of what is represented by form, ranging from 'linguistic' sense to nun-linguistic reference, from meaning to concept, which includes cognition, perception, etc.
} 
'readahle', 'replaceable' - sharing 'V-able' in form and 'being CAPABLE of being V-ed' in meaning), phonesthemes (e.g., 'gleam', 'glance', 'glare', 'glitter', etc. sharing initial /gl/ in form and "connection to vision" in meaning) and so forth, suggest that sameness in form signals sameness in meaning; difference in form signals difference in meaning. Diagrammatic icons are, in this sense, analogous to their objects in structure and/or in relation.

The two examples above indicate two possibilities in which diagrammatic iconicity is manifested in grammar. I shall call them 'structural diagram' and 'relational diagram', which roughly follows Haiman's classification of diagrammatic iconicity into 'motivation' and 'isomorphism' (cf. Haiman, 1985a,b). 'Structural diagrams' display a correspondence between structure of form and structure of content, whereas 'relational diagrams' show a tendency to associate sameness in form with sameness in content; difference in form with difference in content. In an extreme case, this tendency is expressed as the principle of 'one meaning, one form' (cf. Bolinger, 1977). We can see relational diagrams as a special case of structural diagrams, as they presuppose the working of structural analogy. The difference between structural diagrams and relational diagrams seems to be that the former is a structural analogy whereas the latter is a relational analogy. Structural diagrams tend to deal with a correspondence between the structure of linguistic form and the structure of conceptualization; relational diagrams with a correspondence between the relation in linguistic form and the relation in linguistic meaning.

\subsection{Structural diagrams (see Fig. I)}

There are several types of iconicity in which a certain structure of linguistic representation is motivated by its similarity to the content structure it represents. These include linear iconicity, local proximity iconicity, quantity iconicity, symmetrical iconicity, asymmetrical iconicity, and categorical iconicity.

\subsubsection{Linear iconicity}

Linear order of mention corresponds to the temporal sequence of concepts mentioned. When we describe a series of actions occurring in time, the normal sentence reports them in the same order as they occur in reality. So we say,

(1a) John came in and sat down.

and not

(1b) ?John sat down and came in.

\footnotetext{
6 The terminology that I suggest here represents the nature of the two types of diagrammaticity more clearly by avoiding the confusions caused by different interpretations of different researchers for the two terms employed by Haiman, who defines 'motivation' as "ways in which the linguistic form is a diagram of conceptual structure, and homologous with it" (Haiman, 1985b: 2) and 'isomorphism' as "the tendency to associate a single invariant meaning with each single invariant form" (ibid.: p. 4). At the same time, the present classification secures the term 'motivation' for a more general use in which it signifies the 'non-arbitrary' relationship between form and meaning. Ōhori (1987) offers an insightful critique of Haiman's classification of iconicity.
} 


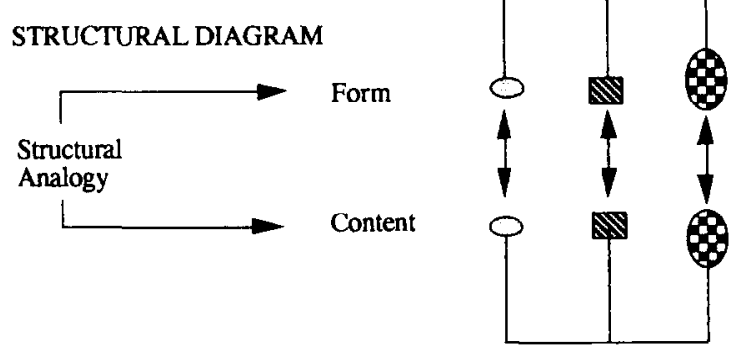

Fig. 1

The conjunction and in these sentences has an asymmetric use, ${ }^{7}$ which clearly promotes the iconic conventions of narrative word order. ${ }^{8}$ It is widely claimed that non-inflectional languages depend more on word order, and thereby on the linear iconicity principle. Tai (1985) claims that the principle of temporal sequence is pervasive in Chinese. That is, "the relative word order between two syntactic units is determined by the temporal order of the states which they represent in the conceptual world" (Tai, 1985: 50).

Linear iconicity also shows up in a set of frozen expressions of two antithetical conjuncts such as 'up and down', 'now and then', 'men and women', etc. Cooper and Ross (1975) demonstrate that in such frozen expressions the properties of the

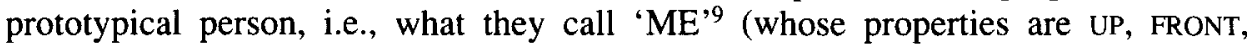
ACTIVE, GOOD, HERE, NOW, etc.), come first. Japanese frozen expressions, in which two conjuncts are put side by side without any conjunction like and, also indicate a similar linear iconicity in which the unmarked comes first, the marked second (cf. Fujii, 1986).

\subsubsection{Local proximity iconicity}

Not only linearity but also proximity of word order suggests iconic interpretation, i.e., elements that occur closer together tend to be semantically closer.

Bybee (1985) demonstrates that there is a universal tendency in which the closeness between verb stems and inflectional categories tends to correspond to the conceptual proximity of the meaning of a verb and the concepts these categories express. The inflectional categories examined in her survey of fifty languages of the

\footnotetext{
7 And itself does not have a temporal meaning. It is the order of segments combined by a narrative usage of and that is iconic to the temporal ordering of the events being narrated.

8 In English, however, with an additional use of an adverbial phrase or a subordinate clause, the same content can be expressed in a reversed order:

(1c) John sat down after he came in.

(1d) Before John sat down, he came in.

This is an issue of competing motivation where given two options of form, we can either use iconic motivation or other motivations such as economical or pragmatic.

9 Concepts are indicated in capital letters, whereas expressions are listed with quotation marks.
} 
world are valence, voice, aspect, tense, mood, agreement of number, of person, and of gender. The result shows that: "(1) The more relevant a category is to the verb, the more likely it is to occur in a synthetic or bound construction with the verb: (2) The more relevant a morphological category is to the verb, the closer its marker will occur with respect to the verb stem: (3) The more relevant a morphological category is to the verb, the greater will be the morpho-phonological fusion of that category with the stem" (Bybee, 1985: 11-12).

Posner (1986) observes an interesting manifestation of proximity iconicity in the order of attributive adjectives to the head noun in English and German. He points out two types of proximity iconicity: (1) "Local proximity to the head noun indicates nouniness" (Posner, 1986: 316); ${ }^{10}$ and (2) "Local proximity indicates semantic closeness" (Posner, 1986: 320). ${ }^{11}$

Lakoff and Johnson (1980: 126-133) discuss similar phenomena from the perspective of a cognitive metaphor, CLOSENESS IS STRENGTH OF EFFECT. ${ }^{12}$ For example, in the sentences like (2a) and (2b) (Lakoff and Johnson, 1980: 129),

(2a) Mary doesn't think he'll leave until tomorrow.

(2b) Mary thinks he won't leave until tomorrow.

(2a) has a weaker negative force than (2b) as the negative marker ' $n$ ' $t$ ' is further away from the verb 'leave' than (2b). Likewise in the following pairs of sentences, the proximity of 'Greek' and 'Harry' suggests a stronger effect of teaching on Harry in (3b) than (3a), and the proximity of 'the chair' and 'comfortable' indicates the directness of the experience with the chair in (4b) but not in (4a) (Lakoff and Johnson, 1980: 130):

(3a) I taught Greek to Harry.

(3b) I taught Harry Greek.

(4a) I found that the chair was comfortable.

(4b) I found the chair comfortable.

10 The more nominal character the attribute has, the closer it stands to the head noun in both postnominal and prenominal modifiers (cf. Posner, 1986: 315) as in:

(a) a heavy English mahogany writing table

(b) a heavy table for writing made of mahogany from England

11 Compare the following two phrases (Posner, 1986: 319):

(a) the uncompleted fourth symphony

[The fourth symphony is uncompleted.]

(b) the fourth uncompleted symphony

[It's the fourth of the uncompleted symphonies.]

The difference of interpretation indicates that the attribute standing nearest to the head noun forms a semantic unit with it. In the same manner, the closer the attribute stands to the head noun, the more dependent its semantic category is on the head noun.

12 Many of the phenomena observed in cognitive linguistics in terms of 'metaphors' can also be classified as Peircean 'diagrams'. For more detailed discussion, see section 4.1. 


\subsubsection{Quantity iconicity}

It is widely recognized that there is an iconic relation between the quantity of form and the quantity (strength, degree) of meaning. Namely, the more form, the more meaning. Examples abound in iteration, repetition, and reduplication of a word or a part of a word to signify plurality, intensity, continuation, etc. (cf. Sapir, 1921: $57-81) .^{13}$

\subsubsection{Symmetrical iconicity}

Symmetrical representation corresponds to the symmetrical relationship of the concepts represented. The very fact that in spoken language linearity is an inescapable property leads us to speculate that the symmetrical relationship of concepts should be the most difficult to represent iconically. However, most languages have some forms expressing symmetry such as simultaneous occurrence, alternative occurrence, and mutual dependency of the concepts denoted. Symmetry is usually expressed in two dimensions: "first, by distinguishing between coordination and backgrounding, and second, by overriding the temporal asymmetry of coordinately conjoined elements through the use of parallel diacritics of various types" (Haiman, 1985a: 102). Compare the following pair of sentences for example:

(5a) The more he eats, the fatter he gets.

(5b) If he eats more, he will get fatter.

Both (a) and (b) express roughly the same thing. The difference between (a) and (b) is that (a) uses coordination to put the conjuncts in parallel, while (b) uses subordination to put the subordinate clause in background. It is easily recognizable that the two conjuncts in (a) are symmetrical whereas those in (b) are asymmetrical. The temporal asymmetry of the two events stated in (a) by the linear iconicity is overridden by the use of parallel diacritics 'the +comparative form of an adjective'. The two elements are lined up in the parallel way, so that they are taken to be equal in rank. ${ }^{14}$

\subsubsection{Asymmetrical iconicity}

Asymmetrical relationships are manifest, to some extent, in linear iconicity and proximity iconicity in which the sequential order or the distance of elements cue the asymmetrical relationship among the content elements. Talmy (1978) observes another type of asymmetry in sentences which reflects a distinction between cognitive-semantic categories of FIGI IRF and GROIND. Compare the following pairs of sentences:

13 Counterexamples abound, too. The extreme case is the problem of zero-form, i.e., ellipsis and silence, which bear meaning. The issue, however, seems too vast and complicated to be properly handled in this brief article.

14 Still we cannot fully escape from the linear iconicity in (5a) where what is expressed by the first conjunct occurs first, and the second conjunct second. Compare (5a) and $(5 \mathrm{c})$, for example:

(5a) The more he eats, the fatter he gets.

(5c) The fattcr he gets, the more he eats.

The semantic difference between $(5 a)$ and $(5 c)$ depends on the linear iconicity of the two conjuncts. 
(6a) The bike is near the house.

(6b) 'The house is near the bike. (Talmy, 1978: 628)

(7a) John resembles his father.

(7b) 'John's father resembles John.

Sentences (a) and (b) are not synonymous. The asymmetrical relationship of the cognitive categories of 'the bike' and 'the house', and of 'John' and 'John's father' - the first, variable element, and the other, reference element - makes (a) possible but not (b) in an ordinary context. 'The bike' and 'John' are FIGURE; 'the house' and 'John's father' are GROUND. In simple sentences like the above, FIGURE is expressed as a topic and GROUND as a part of a comment. Hence, there is a diagrammatic correspondence between topic/comment representation and FIGURE/GROUND cognition.

A similar rule holds true with complex sentences in which the main clause corresponds to FIGURE and the subordinate clause to GROUND as in the following:

(8a) He dreamt while he slept.

(8b) *He slept while he dreamt. (Talmy, 1978: 636)

In $(8 b)$ the function of foregrounding of the main clause conflicts with the cognitive category of GROUND 'he slept'. The asymmetry of the two cognitive events, 'he dreamt' and 'he slept' can also be represented by a different asymmetrical grammatical structure such as in $(8 \mathrm{c})$ :

(8c) He dreamt during his sleep.

The category of GROUND can be expressed by a simpler and shorter form such as an adverbial phrase which consists of a preposition and a nominalized phrase as in $(8 \mathrm{c})$, but not the category of FIGURE as in (8d).

(8d) *His dream while he slept.

\subsubsection{Categorical iconicity}

It seems that what cognitive linguistics claims about the relationship of linguistic categorization and cognitive categorization can be interpreted along the line of diagrammatic iconicity, too. Categorization in language corresponds to the way we conceptualize the world. Lakoff $(1987$ : 58) argues that "linguistic categories should be of the same type as other categories in our conceptual system ... . Evidence about the nature of linguistic categories should contribute to a general understanding of cognitive categories in general". The basic premise of his methodology of using linguistic categories to understand cognitive categories presupposes that there is a correspondence between the two. This correspondence can be taken as diagrammatic because the linguistic categories and the cognitive categories are "of the 
same type". It is the sameness of type held between cognition and language that suggests structural diagrammaticity. ${ }^{15}$

One way in which the correlation between cognition and language is manifest is where a 'basic/non-basic' asymmetry in the cognitive categories is represented by a 'marked/unmarked' asymmetry in the linguistic categories. ${ }^{16}$ For example, a basic number, singularity, is expressed by no marker, whereas a non-basic number, plurality, is expressed by a marker in most languages. A basic tense, present tense, is semantically 'unmarked' and tends to have no overt marker, while non-basic tenses, past and future, are semantically 'marked' and tend to have an overt marker. Thus, a cognitively basic or 'unmarked' notion tends to take an 'unmarked' form; a non-basic or 'marked' notion tends to take a 'marked' form.

\subsection{Relational diagrams (see Fig. 2)}

A principle of relational diagrams can be stated in the following way: sameness in form signals sameness in meaning, whereas difference in form signals difference in meaning. This principle, compared to the principle of structural diagrams discussed in the previous section, deals more with the inner relationship of forms in a language in respect to the inner relationship of meaning expressed.

As indicated above, this isomorphic principle has two components: (i) difference in form reflects difference in meaning; and (ii) sameness in form reflects sameness in meaning.

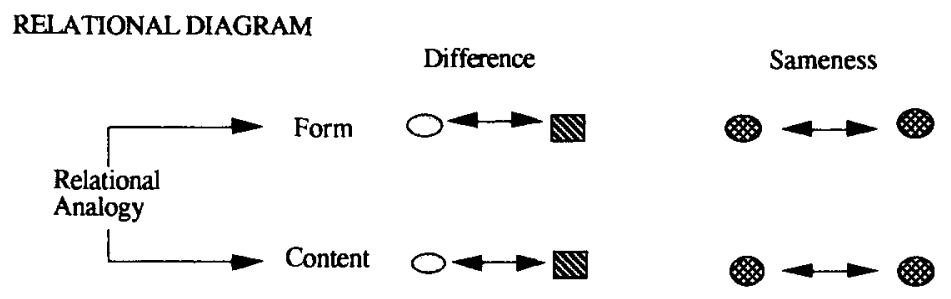

Fig. 2

\subsubsection{Difference of form}

A difference in form cues a difference in meaning, but it does not cue the nature nor the degree of the difference. When two words or sentences are different in form,

15 Lakoff (1987: 113-114) lists four cognitive models by which human categories are characterized: propositional, image-schematic, metaphoric and metonymic models. It is assumed that the linguistic categories give evidence for the existence of these four models which, at the same time, reflect the nature of the cognitive categories.

16 Markedness is used in two ways in the literature: (1) formal markers, e.g., overt markers vs. no overt markers; and (2) markedness in semantics, pragmatics, cognition, etc. The second type of markedness, which I refer alternatively as 'basic/non-basic asymmetry', is not necessarily represented by the first type. It is also indicated by word order, contextual differentiation, etc. 
they indicate that they mean different things. This has been challenged by the claim that there are synonyms and paraphrases in language.

Bolinger (1977) meets this challenge by demonstrating that "there is no difference in form without some difference in meaning" (Bolinger, 1977: vi) with a number of examples from English and Spanish. Haiman (1985a: 21) also argues that total synonymy is rare in language.

Let me briefly list a few of Bolinger's (1977: 10-14) examples:

(9a) Waiting would have been a mistake.

(9b) Waiting has been a mistake.

(10a) To wait would have been a mistake.

(10b) *To wait has been a mistake.

[Contradicting the 'hypothetical' meaning attached to the infinitive]

(10b) contradicts the claim that the gerund and the infinitive are synonymous.

(11a) George turned the pages.

(llb) The pages were turned by George.

[Effect being produced on the patient, i.e., something happened to the pages in the process]

(12a) George turned the corner.

(12b) *The corner was turned by George.

[Effect not being produced on the patient]

This contradicts the claim that the active voice and the passive voice are synonymous.

\subsubsection{Sameness of form}

Similarity in form signals similarity in meaning. Waugh and Newfield (to appear) demonstrate that the lexicon is pervaded by a host of associations between words based on form-meaning connections, which particularly result in word-affinity relations.

For example, an initial /fl-/ (phonestheme) in English is expressive of movement and characterizes a whole family of words:

(13) flap, flare, flee, flick, flicker, fling, flip, flit, flitter, flow, flutter, fly

Word-constellations of the grammatical lexicon of demonstratives and interrogatives indicate an isomorphic association of meaning cued by sameness of form.

(14) the, this, that, they, their, thee, thou, thy, thine, then, there, thus, than, though (Bloomfield, 1933: 47, 244)

(15) what, why, when, where, which, whether, how (Jakobson and Waugh, 1979: 55)

Waugh and Newfield (to appear) further argue that many of such word affinity phenomena are best understood as being based on a paradigmatic network of corre- 
spondence between form and meaning in words as a gestalt (unified whole), rather than on a syntagmatic analysis of correspondence between form and meaning in segmentable morphemes.

\section{Metaphorical iconicity}

Metaphor is discussed very briefly by Peirce. Aside from the definition given above (see n. 4), there are only a few descriptions of metaphors in his writings, in contrast to his recurrent explanations about and descriptions of images and diagrams. Metaphors are different from images and diagrams in that they require an existence of 'something else', i.e., a third thing in addition to a sign and the object. In this sense, it is by a triadic relation that metaphors achieve their signification. To repeat the example listed before, a metaphorical icon (e.g., "My love is a rose") signifies its object (e.g., 'my love') by pointing to a parallelism between the object (e.g., 'my love') and something else (e.g., 'a rose').

In theory, it seems that the differences among images, diagrams and metaphors are as clear as stated above. However, in concrete examples of any iconic sign, the distinction appears to be fuzzy as we often encounter examples which show greater or lesser mixtures of these subtypes of icons. The following discussion will demonstrate that metaphorical signs, with special emphasis on conventional and poetic metaphors, manifest all three aspects of icons.

\subsection{Grammatical metaphors}

As discussed before (see section 3.1.2 in particular), the way diagrammatic iconicity is manifested in grammar can also be interpreted as metaphorical iconicity because it involves a mapping of one domain onto another such as the experiential (temporal and spatial) onto the formal (grammatical), or the conceptual (cognitive) onto the linguistic. The researcher's emphasis of one aspect or another determines whether an iconic link belongs to one or the other of the categories of icon. In other words, the iconic correspondences that we have observed so far display both diagrammatic and metaphorical aspects and the difference is just a degree of predominance of one or the other.

Langacker (1987: 39) also points out that "grammar embodies conventional imagery". What he meant by 'imagery' is equivalent with 'metaphor' in our usage, as he further elaborates it by saying that "[imagery] structures a scene in a particular way for purposes of linguistic expression, emphasizing certain facets of it at the expense of others, viewing it from a certain perspective, or construing it in terms of a certain metaphor" (ibid.). This image-metaphor is useful when explaining the subtle semantic differences between the following two sentences:

(16a) He sent a letter to Susan.

(16b) He sent Susan a letter. 
Langacker explains that hecause of the use of the preposition 'to' in (16a), it highlights the PATH traveled by the letter with Susan as a GOAL, whereas (16b) highlights the proximity of Susan and a letter, namely, the possession of the letter by Susan with a juxtaposition of the two nominals.

More complex metaphorical transfers/extensions are observed cross-linguistically in vocabulary, in grammatical structures, and in pragmatic discourses (cf. Claudi and Heine, 1986; Sweetser, 1990; Ōhori, 1991). One of such metaphorical transfers is a SPATIAL-TEMPORAL-CAUSAL extension in polysemy and other grammatical constructions.

The Japanese particle kara ('from'), for example, displays a polysemy which can be explicated by a metaphorical extension from PLACE to TIME, and to CAUSATION.

(17a) Watashi wa Tokyo kara ki-mashi-ta. [SOURCEplace]

I TOPIC Tokyo from come-POLITE-PAST 'I came from Tokyo.'

(17b) Kaigi wa san-ji kara hajimari-masu. [SOURCEtime] meeting TOPIC three o'clock from begin-POLITE.PRESENT. 'The meeting begins at three.'

(17c) Kore wa yoi hon da kara, yomi-nasai. [SOURCEcausation] this TOPIC good book be from, read-POLITE.IMPERATIVE 'Because this is a good book, read it.'

Note that in (17a) and (17b), kara is a postpositional particle, whereas in (17c) the same item appears as a subordinate connective which conjoins two propositions. It is as if the subordinated proposition in $(17 \mathrm{c})$ were taken as a spatial/temporal entity. SOURCE in a spatial domain is mapped onto a temporal domain in (17b) and to a logical domain in $(17 \mathrm{c})$. Consequently, the grammatical constructions produced by the polysemic metaphorical extension of the Japanese particle kara are motivated by the cognitive metaphors such as TIME IS PLACE, CAUSATION IS PLACE, and PROPOSITION IS PLACE.

Claudi and Heine (1986) extensively investigate the role played by metaphor in the rise of grammatical morphology in Ewe. They claim, for example, that cognitive metaphors are useful to account for desemanticization in which a given lexical unit loses in semantic complexity and tends to be reduced to a grammatical marker, as illustrated in Ewe case marking. The verb ná ('give') in (18a) is desemanticized to the preposition ná ('to') which marks a dative case in (18b) and (18c) (cf. Claudi and Heine, 1986: 319).

(18a) é -ná ga m he-give money me 'He gave me money.'

(18b) é -fi ga ná m he-steal money give me 'He stole money for me.'

(18c) me -øle Botrú ná aøé lá I -buy door to home DEF 'I bought a door for the home.' 
There are metaphors such as A QUALITY IS A PROCESS and AN OBJECT IS A PERSON behind the desemanticization of ná from a full verb to a preposition.

Thus, in the words of Lakoff and Johnson (1980: 138), "metaphor gives meaning to form" and "syntax is not independent of meaning, especially metaphorical aspects of meaning".

\subsection{Conventional metaphors}

Metaphors are pervasive in language in both conventionalized and creative manifestations. When particular metaphors become conventionalized, they are felt to be literal. That is, the burden of discovering the parallelism is no longer felt between the object of metaphor and 'something else'. Then the parallelism can be seen as a diagram, bearing one-to-one correspondence decoded by convention. Some conventions vary from culture to culture, while others remain rather universal (cf. Hiraga, 1991). When a metaphor is a novel and creative one, on the other hand, it seems we are more dependent on imagination than convention in the discovery of similarities, for the similarity relation in a creative metaphor is ambiguous, yielding multiple possibilities of interpretation.

Cognitive linguistics is particularly concerned with conventionalized metaphors. ${ }^{17}$ The basic claim is that "metaphor is ... not just in language but in thought and action" (Lakoff and Johnson, 1980: 3). Metaphors are put on the cognitive plane where human concepts or thoughts are formed, processed, and developed. In other words, the concept is structured, in a large part, metaphorically. And because of these metaphorically structured concepts, we experience things in terms of metaphors. Furthermore, because of these metaphorically structured concepts, we speak about things in terms of metaphors. The relationship between metaphorical concepts and metaphorical expressions can be described thus: "metaphors as linguistic expressions are possible precisely because there are metaphors in a person's conceptual system"' (Lakoff and Johnson, 1980: 6). ${ }^{18}$ Here we can point out two parallel diagrams - one to be held between metaphorical concepts and metaphorical expressions, the other between the two domains of concepts (and of expressions) in conventional metaphors - because each presupposes a one-to-one correspondence between the two elements compared.

Let us take a metaphor, LIFE IS A GAME, for example. The structure of the domain to be understood (i.e., LIFE) and the structure of the domain in terms of which we are understanding (i.e., GAME) have a fixed correspondence such as:

(19a) Life has a beginning and an end just as games do.

(19b) There are rules you must observe.

(19c) You win or lose.

17 Lakoff and Turner (1989) deal with the relationship of conventionalized metaphors and creative metaphors. For further discussion, see section 4.3.

18 Note that the relationslip of cognition and of linguistic expressions is a diagramnatically mapped one. Metaphor concerns the way in which the concepts are categorized. 
(19d) You must follow certain tactics.

(19e) Failure in life is like a loss in the game.

(19f) Advance in life is a like gain in the game.

$(19 \mathrm{~g})$ Both are fun and enjoyable.

Thus, the way the cognitive structure of the GAME domain corresponds to that of the LIFE domain is just like a diagram which bears a structurally analogical relationship.

The relationship of the conceptual metaphor LIFE IS A GAME and the metaphorical expressions listed below also shows a diagrammatic correspondence, where the properties highlighted by the metaphor take linguistic manifestations.

(20a) IIe is a real loser in life. ${ }^{19}$

(20b) He won every game of life to reach the top.

(20c) You must observe the rules in doing anything.

(20d) He struck out in his last two business ventures. ${ }^{20}$

(20e) If you don't dress neatly, you won't get to first base when you look for a job.

(20f) I had to pinch-hit for our chairman.

Metaphors display an imagic aspect, too. In the LIFE IS A GAME metaphor, the image of a game (a baseball game in particular) is shared by the image of life as an activity which occurs in time and space within a boundary. The correspondence of these two images seems more immediate than diagrams.

Needless to say, cognitive metaphors bear the property of Peircean metaphor (see n. 4) in that they represent a parallelism between the two domains combined by association. In the LIFE IS A GAME metaphor, we understand the object, LIFE, by the mediation of 'something else', i.e., A GAME. It is not just a direct sensory understanding of LIFE as such, like a Peircean image, nor just a coded isomorphic understanding of LIFE as A GAME. Being a metaphor, in order to 'make sense', it requires a discovery of the similarities brought into light by the parallelism represented by the metaphor.

\subsection{Poetic metaphors}

We have seen so far that iconicity is pervasive at various levels in ordinary language, although we are not always fully aware of it. In poetic language, on the other hand, iconicity is the rule. It is foregrounded as one of the principles governing the structure of the poetic text. Image and diagrammatic iconicity in poetry has been the focus of an enormous amount of endeavor in linguistic poetics (cf. Jakobson, 1962, 1971, 1980; Jakobson and Waugh, 1979; Jakobson and Rudy, 1980; Hiraga, 1987, 1990, 1993a,b).

For an understanding of poetic metaphors along the lines of iconicity research, linguistic poetics, developing under the influence of cognitive science on the one hand

\footnotetext{
19 Metaphorical linguistic expressions are indicated in italics.

20 Examples from (20d) to (20f) are based on a subcatcgory of the LIIT: is A GAML metaphor, namely, LIFE IS A BASEBALL GAME.
} 
(cf. Turner, 1987; Lakoff and Turner, 1989; Turner, 1991; Freeman, in preparation) and Peircean semiotics on the other (cf. Shapiro, 1976; Haley, 1988), offers much insight into the structuring power of poetic metaphor.

Lakoff and Turner (1989), for example, demonstrate how basic conceptual metaphors, which underlie everyday expressions, also underlie many poetic metaphors and how they serve in part to give the power that poetic metaphors disclose. They also clarify the ways in which poetic metaphors differ from conventional metaphors, such as: (1) novel extension of a conventional metaphor, (2) nonconventional elaboration of image-schemas by filling special or unusual cases, (3) questioning of the limitations of conventional metaphors and offering of a new one, and (4) formation of composite metaphors by the non-conventional combination of multiple conventional metaphors for a given target domain (cf. Lakoff and Tumer, 1989: 67-72). Indeed, their pioneer work has forged our understanding of the way in which metaphors, both as concepts and as images, ${ }^{21}$ structure the poetic text, and the way in which a poem is structured as a metaphorical icon of the overall meaning that it represents.

Haley (1988), on the other hand, incorporates Peircean semiotics into the study of poetic metaphors to argue that poetic metaphors manifest themselves as what Peirce has called the 'complete sign', in which symbolic, iconic and indexical layers are blended interactively (cf. Haley, 1988: 53). By interpreting a Peircean 'symbol' as being partly 'motivated' by its 'iconic' and 'indexical' ingredients, Haley claims that poetic metaphor is a symbol which has an 'iconic' core and which grows its cognitive and linguistic dimensions through the mediating function of 'indexical' stretching of semantic space. The semantic tension created by poetic metaphor is symbolic, iconic and indexical in nature. It is dependent on convention both linguistically and culturally [the symbolic layer]; it suggests a similarity between the two terms put in tension [the iconic layer]; and at the same time, it points to a clash of dissimilarities between the two terms in actuality [the indexical layer]. By analyzing how this indexical expansion of metaphorical iconicity takes place in various poetic texts, Haley succeeds in the explication of the dynamic semeiosis of poetic metaphor.

\section{Concluding remarks}

Diagrammatic and metaphorical iconicity is manifest on all levels - phonological, morphological, lexical, syntactic, conceptual, pragmatic - in synchronic and diachronic dimensions, and in ordinary and poetic language. The degree of iconicity may vary from example to example, from level to level, from language to language. It seems legitimate to assume that there is a continuum of bipolarity between iconicity and arbitrariness. Certain form-content relations are highly iconically motivated, others hold a highly arbitrary relationship, and still many others are in between these two poles (cf. Waugh, 1991).

21 It seems to me that what Lakoff and Turner (1989: 89-100) call 'image-mapping' corresponds to 'image iconicity' and 'conceptual mapping' to 'diagrammatic iconicity', and that these two kinds of mapping interact with 'metaphorical iconicity' in poetic metaphors. 
There also is the problem of competing motivations - such as iconic motivation and economic motivation (cf. Haiman, 1985a: 157-261) - to be dealt in the context of iconicity research. Those motivations which compete with iconic ones contribute to increasing arbitrariness. They include generalization, simplification, distortion, and so forth. ${ }^{22}$

As Haiman (1985a: 7-8) puts it, the discussion of arbitrariness and motivation depends, to a large extent, on the data that researchers choose to consider interesting or significant. In this regard, a common premise shared by iconicity studies is that language should be investigated in a broad human context, such as in relation to semiotics, psychology, and/or cognition, rather than in isolation. It is a natural tendency of the human mind to associate similar things together and to make sense out of them. Thus, the explanations given to the iconic relationship between form and content have a strong bearing on the natural and universal nature of language.

\section{References}

Bloomfield, Leonard, 1933. Language. New York: Holt, Rinehart, and Winston.

Bolinger, Dwight, 1977. Meaning and form. London: Longman.

Bybee, Joan L., 1985. Diagrammatic iconicity in stem-inflection relations. In: John Haiman, ed., Iconicity in syntax, 11-47. Amsterdam: Benjamins.

Claudi, Ulrike and Bernd Heine, 1986. On the metaphorical base of grammar. Studies in Language, 10(2): 297-335.

Cooper, William E. and John Robert Ross, 1975. World order. In: Robin E. Grossman, L. James San and Timothy J. Vance, eds., Functionalism, 63-111. Chicago, IL: Chicago Linguistic Society.

Freeman, Donald C., in preparation. Shakespeare and human understanding: A study in cognitive metaphor.

Fujii, Yoko, 1986. A comparative study of 'freeze' in Japanese and English. In: John H. Koo and Robert N. St. Clair, eds., Cross-cultural communication: East and west, Vol. 1: 335-355.

Givón, Talmy, 1985. Iconicity, isomorphism, and non-arbitrary coding in syntax. In: John Haiman, ed., Iconicity in syntax, 187-219. Amsterdam: Benjamins.

Haiman, John, ed., 1985b. Iconicity in syntax. Amsterdam: Benjamins.

Haley, Michael C., 1988. The semeiosis of poetic metaphor. Bloomington, IN: Indiana University Press. Hiraga, Masako K., 1987. The hidden melodies: A linguistic analysis of a Japanese tanka. In: Werner Bahner, Joachim Schildt and Dieter Viehweger, eds., Proceedings of the Fourteenth International Congress of Linguists, 1945-1949. Berlin: Akademie-Verlag.

Hiraga, Masako K., 1990. Sound as meaning: Iconicity in Edgar Allan Poe's 'The Bells'. The Journal of the University of the Air 8: 1-23.

Hiraga, Masako K., 1991. Metaphor and comparative cultures. In: Paul George Fendos, Jr., ed., Crosscultural communication: East and west, Vol. 3, 149-166. Tainan: T'ai Ch'eng Publishing. [Distributed by the Department of Foreign Languages and Literature, National Cheng-Kung University, Tainan, Taiwan.]

Hiraga, Masako K., 1992. Shi ni okeru ruizōsei ni tsuite [On iconicity in poetry]. Kigōgaku Kenkyū [Studia Semiotica: The Journal of the Japanese Association for Semiotic Studies] 12: 73-86.

Hiraga, Masako K., 1993a. Iconicity in poetry: How poetic form embodies meaning. In: K. Haworth, J. Deely and T. Prewitt, eds., Semiotics 1990: The Proceedings of the 15th Annual Meeting of the Semiotic Society of America, 115-126. New York: University Press of America.

22 For a discussion of competing motivations, see Haiman (1985a,b), and Givón (1985). 
Hiraga, Masako K., 1993b. Iconic meanings of visual repetition in poetry. Semiotics. In: J. Deely and T. Prewitt, eds., Semiotics 1991: The Proceedings of the 16th Annual Meeting of the Semiotic Society of America, 95-105. New York: University Press of America.

Jakobson, Roman, 1962. Selected writings III. The Hague: Mouton.

Jakobson, Roman, 1971. Slected writings V. The Hague: Mouton.

Jakobson, Roman, 1971[1966]. Quest for the essence of language. Selected writings II, 345-359. The Hague: Mouton.

Jakobson, Roman, 1980. Subliminal verbal patterning in poetry. In: K. Pomorska and S. Rudy, eds., Verbal art, verbal sign, verbal time, 59-68. Minneapolis, MN: University of Minnesota Press.

Jakobson, Roman and Linda R. Waugh, 1979. The sound shape of language. Bloomington, IN: Indiana University Press.

Jakobson, Roman and Stephan Rudy, 1980. Yeats' 'Sorrow of Love' through the years. In: K. Pomorska and S. Ruday, eds., Verbal art, verbal sign, verbal time, 79-107. Minneapolis, MN: University of Minnesota Press.

Lakoff, George, 1987. Woman, fire, and dangerous things: What categories reveal about the mind. Chicago, IL: Chicago University Press.

Lakoff, George and Mark Johnson, 1980. Metaphors we live by. Chicago, IL: Chicago University Press.

Lakoff, George and Mark Turner, 1989. More than cool reason: A field guide to poetic metaphor. Chicago, IL: Chicago University Press.

Langacker, Ronald W., 1987. Foundations of cognitive grammar, Vol. 1. Stanford, CA: Stanford University Press.

Langacker, Ronald W., 1991. Foundations of cognitive grammar, Vol. 2. Stanford, CA: Stanford University Press.

Ōhori, Toshio, 1987. On the concept of iconicity in the study of language. Language, Culture and Communication 2: 34-50. Keio University.

Ōhori, Toshio, 1991. Bumpō kōzō no ruizōsei [Iconicity in grammatical structures]. Kigōgaku Kenkyū [Studia Semiotica: The Journal of the Japanese Association for Semiotic Studies] 11: 95-107.

Peirce, Charles S., 1955 [1902]. Logic and semiotic: Theory of signs. In: J. Buchler, ed., Philosophical writings, 98-119. New York: Dover.

Plato, 1926. 'Cratylus'. Plato, Vol, IV. H.N. Fowler, trans. London: William Heinemann.

Posner, Roland, 1986. Iconicity in syntax. In: Paul Bouissac et al., eds., Iconicity: Essays on the nature of culture, 305-337. Tübingen: Stauffenburg.

Sapir, Edward, 1921. Language: An introduction to the study of speech. New York: Harcourt, Brace and World.

de Saussure, Ferdinand, 1959 [1916]. Course in general linguistics. Wade Baskin, trans. New York: McGraw-Hill.

Shapiro, Michael, 1976. Asymmetry: An inquiry into the linguistic structure of poetry. Amsterdam: North-Holland.

Tai, James H-Y., 1985. Temporal sequence and Chinese word order. In: John Haiman, ed., Iconicity in syntax, 49-72. Amsterdam: Benjamins.

Talmy, Leonard, 1978. Figure and ground in complex sentences. In: Joseph H. Greenberg, ed., Universals of human language, Vol. 4, 625-649. Stanford, CA: Stanford University Press.

Turner, Mark. 1987. Death is the mother of beauty. Chicago, IL: Chicagn University Press.

Turner, Mark, 1991. Reading minds. Princeton, NJ: Princeton University Press.

Waugh, Linda R., 1991. Let's take the con out of iconicity: Constraints on iconicity in the lexicon. Presidential address at 1991 Annual Meeting of the Semiotic Society of America.

Waugh, Linda R. and Madeleine Newfield, to appear. Iconicity in the lexicon and its relevance for a theory of morphology. In: Marge Landsberg, ed., Iconicity in syntax. Berlin: Mouton de Gruyter. 